\title{
Use of biomarkers of sub-clinical infection, nutrition and neonatal maturity to interpret plasma retinol in Nigerian neonates
}

\author{
Delana A. Adelekan ${ }^{1}$, Christine A. Northrop-Clewes ${ }^{3}$, Joshua A. Owa ${ }^{2}$, Adesola O. Oyedeji ${ }^{4}$, \\ Adedayo A. Owoeye ${ }^{4}$ and David I. Thurnham ${ }^{3 *}$ \\ ${ }^{1}$ Department of Community Health and ${ }^{2}$ Department of Paediatrics and Child Health, Obafemi Awolowo, \\ University Ile-Ife, Nigeria \\ ${ }^{3}$ Northern Ireland Centre for Diet and Health (NICHE), University of UIster, Coleraine BT52 1SA, Northern Ireland, \\ UK \\ ${ }^{4}$ Department of Paediatrics, Wesley Guild Hospital, Ilesa, Nigeria
}

(Received 26 June 2002 - Revised 17 March 2003 - Accepted 9 April 2003)

\begin{abstract}
Using the World Health Organization criterion, the prevalence of sub-clinical vitamin A deficiency can be assessed using plasma retinol concentrations $<0.7 \mu \mathrm{mol} / \mathrm{l}$. However, plasma retinol can be depressed by infection; thus, the use of this criterion alone may overestimate deficiency. In the present study, we investigated the usefulness of the acute-phase proteins (APP) $\alpha_{1}$-antichymotrypsin (ACT) and $\alpha_{1}$-acid glycoprotein (AGP), plasma carotenoids and anthropometric and gestational indices to interpret plasma retinol in the blood of 192 apparently healthy Nigerian neonates collected randomly during days $1-20$ postpartum. The mean weight $(2.64 \mathrm{~kg})$ and length $(0.458 \mathrm{~m})$ of the neonates and plasma concentrations (geometric mean, $\mu \mathrm{mol} / \mathrm{l})$ of retinol $(0.54), \alpha$-carotene $(0.072), \beta$-carotene $(0.076)$ and lutein $(0.080)$ were low. The prevalence of vitamin A deficiency was $72 \%$, indicating a severe public health problem. Babies who were of low birth weight $(P<0.003)$ or premature and low birth weight $(P<0.023)$ had significantly lower retinol concentrations than full-term normal weight babies. Thirty-two neonates had abnormal ACT and forty-four abnormal AGP concentrations. Positive correlations between retinol and ACT $(r 0 \cdot 186, P=0.05)$ and $\operatorname{AGP}(r 0.31, P=0 \cdot 0001)$ during days $1-5$ may be due to the increasing plasma retinol from maternal milk and a coincidental increasing capacity to synthesise APP. Subsequently, negative correlations between retinol and ACT $(r-0.28, P=0.02)$ and AGP $(r-0.29, P=0.018)$ from day 6 onwards reflected the continuing increase in plasma retinol, but no further increase in the APP. Overall, weight, ACT, lutein and age explained $30 \%$ of the variance in retinol, but lutein was the most significant $\left(r^{2} 0 \cdot 18, P<0 \cdot 0001\right)$. Hence, the distribution of plasma retinol concentrations in this group of neonates was more strongly linked with nutrition (via the surrogate marker lutein) than infection.
\end{abstract}

Retinol: Lutein: Acute-phase proteins: $\alpha_{1}$-Antichymotrypsin: $\alpha_{1}$-Acid glycoprotein: Nigeria: Neonate

Vitamin A deficiency (VAD) continues to be a public health problem in many countries in the tropics and subtropics. The only available national data on vitamin A status in Nigeria are from a survey carried out in 1994, in specific areas of each of the four main health zones (2836 subjects). The surveys found a prevalence of $0.2 \%$ xerophthalmiarelated corneal scars in children aged $0-6$ years; hence, Nigeria is listed by the World Health Organization as one of the category 1 countries having the highest risk of VAD (United Nations International Children's Emergency Fund, 1994). Results from the same survey indicated the overall prevalence of sub-clinical VAD in mothers, based on plasma retinol $<0.7 \mu \mathrm{mol} / 1$, was $9.2 \%$ (mild deficiency) but was slightly higher in the north-east of the country, where it was $14.0 \%$ (moderate deficiency) (World Health Organization, 1996). Individual studies on preschool children suggest that the problem of sub-clinical
VAD varies in different areas of the country, with a severe public health problem in eastern Nigeria (25.4\%; Uzoechina \& Okoro, 1994), but a more moderate situation in the south-west (11.3\%; Adelekan et al. 1997). However, there appears to be no results available on plasma retinol in Nigerian neonates, although Coutsoudis et al. (1995) in Durban (South Africa) reported that $78 \%$ of neonates had plasma retinol values $<0.35 \mu \mathrm{mol} / 1$.

Plasma retinol can be used as a crude indicator of vitamin A status (particularly when concentrations are low); however, infection and/or trauma can depress plasma retinol. Therefore, the use of indices such as plasma retinol $<0.7$ or $<0.35 \mu \mathrm{mol} / 1$ may overestimate the prevalence of VAD (Thurnham \& Singkamani, 1991). In developing countries, frequent exposure to infection is common and the prevalence of sub-clinical infection is likely to be high. Previous work has shown that $\alpha_{1}$-acid glycoprotein 
(AGP) was useful in interpreting plasma retinol in Ghana (Filteau et al. 1995) and Pakistan (Paracha et al. 2000). In addition to infection, prematurity and low birth weight may influence plasma retinol concentrations, as reported by workers in Saudi Arabia (Tolba et al. 1998), South Africa (Coutsoudis et al. 1995, 2000) and the UK (Chan et al. 1993).

The objective of the present study was to investigate vitamin A status in Nigerian neonates. To do this, blood was collected from infants in the first few days of life and plasma retinol was measured. Concentrations of plasma carotenoids and acute-phase proteins (APP) were determined because of their potential value as indicators of vitamin A nutrition (Thurnham et al. 1998) or inflammatory status (Filteau et al. 1995; Paracha et al. 2000). In addition, body weight, gestational age and prematurity were also investigated because of associations with plasma retinol concentrations reported in the literature. The results obtained provide information on the prevalence of VAD in Nigerian neonates and the present report describes how various factors were used to interpret vitamin A status. Understanding the factors that influence plasma retinol concentrations in neonates is essential to developing nutritional strategies. A short report of the present study was presented at the XXth International Vitamin A Consultative Group Meeting (Adelekan et al. 2002).

\section{Subjects and methods}

\section{Subjects}

Blood samples were obtained from 205 neonates between July 1996 and August 1997 when ad hoc visits were made to the labour, postnatal and neonatal wards in an attempt to collect a representative sample of infants found in the wards. The infants were recruited at the Wesley Guild Hospital, Ilesa, Nigeria, which is part of the Obafemi Awolowo University Teaching Hospitals Complex, Ile-Ife, in south-west Nigeria. About 3000 women per year attend the antenatal clinic at the hospital, of which approximately $70 \%$ ( $n$ 2000) deliver there. The majority $(75 \%)$ of neonates were aged $0-6 \mathrm{~d}(n 152)$ at the time of the blood sampling and $25 \%$ of neonates were older $(6-20 \mathrm{~d})$. All neonates were apparently well at recruitment and were exclusively breast-fed except for twenty, who were given combined breast- and formulafeeding.

\section{Ethical approval}

Ethical approval was obtained from the Research Ethics Committee of the College of Health Sciences at the Obafemi Awolowo University, Ile-Ife, Nigeria. Each mother enrolled into the study gave informed written consent.

\section{Blood sampling}

At recruitment, $0.5-1.0 \mathrm{ml}$ venous blood was drawn from the heel of each neonate into heparinised tubes. Blood samples were mixed gently on a roller mixer and then centrifuged at $1200 \mathrm{~g}$ for $5 \mathrm{~min}$ to separate plasma and erythrocytes. Plasma was stored frozen at $-50{ }^{\circ} \mathrm{C}$ for up to 9 months before shipment on dry-ice for analyses of fat-soluble vitamins, carotenoids and APP at the Northern Ireland Centre for Diet and Health, University of Ulster, Coleraine, Northern Ireland, UK. Samples were subsequently stored at $-70^{\circ} \mathrm{C}$ until analysis (approximately 6 months).

\section{Determination of plasma fat-soluble vitamins}

The concentrations of fat-soluble vitamins $\mathrm{A}$ and $\mathrm{E}$ and carotenoids in $0.1 \mathrm{ml}$ plasma were determined by HPLC by the method of Thurnham et al. (1988), modified to include the measurement of lutein. Lutein in this system elutes in a combined peak with zeaxanthin. Reagents included HPLC-grade ethanol, methanol, dichloromethane, acetonitrile, heptane and hexane (E. Merck, Poole, Dorset, UK). The standards used were retinol, $\alpha$-carotene, $\beta$-carotene, lycopene, tocopherol, tocopheryl acetate (E. Merck), ß-cryptoxanthin and lutein (gifts from Hoffmann-La Roche Ltd, Basel, Switzerland).

Briefly, $0.1 \mathrm{ml}$ plasma was mixed with $0.1 \mathrm{ml}$ aqueous SDS $(10 \mathrm{~mm})$ and $0.2 \mathrm{ml}$ internal standard $(84 \mu \mathrm{mol}$ tocopheryl acetate/l ethanol). The micronutrients were extracted into $1.0 \mathrm{ml}$ heptane containing $0.5 \mathrm{~g}$ butylated hydroxytoluene/l. The stoppered tubes were vortexed for $5 \mathrm{~min}$ and centrifuged for $10 \mathrm{~min}$ at $1000 \mathrm{rpm}(2500 \mathrm{~g})$ at $10^{\circ} \mathrm{C}$. The upper heptane layer $(0.7 \mathrm{ml})$ was removed and dried down under $\mathrm{N}_{2}$ at $40^{\circ} \mathrm{C}$. The samples were reconstituted with $100 \mu \mathrm{l}$ mobile phase (acetonitrile-methanoldichloromethane (47:47:12, by vol.)) and $50 \mu \mathrm{l}$ was injected automatically onto a $3 \mu \mathrm{m}$ Spherisorb ODS-2 column $(100 \times 4 \mathrm{~mm}$; Phase Separations Ltd, Clwyd, Wales, UK), separated at a flow rate of $1.0 \mathrm{ml} / \mathrm{min}$ and the micronutrients detected using two channels of a Waters 490 detector (Millipore UK Ltd, Watford, Herts., UK). The intra-batch $\mathrm{CV}$ of a pooled plasma sample were found to be (\%): retinol 5.8 (mean value $0.98 \mu \mathrm{mol} / \mathrm{l}$ ); lutein 6.9 (mean value $0.46 \mu \mathrm{mol} / \mathrm{l}$ ); $\alpha$-carotene 11.2 (mean value $0.04 \mu \mathrm{mol} / \mathrm{l}$ ); $\beta$-carotene 5.8 (mean value $0.36 \mu \mathrm{mol} / \mathrm{l})$.

\section{Determination of plasma acute-phase proteins}

The concentrations of ACT and AGP were determined turbidimetrically (Dako, Ely, Cambs., UK). Plasma was diluted 1:41 with dilution buffer (S2005; Dako). ACT rabbit anti-human antibody was diluted $1 \cdot 0: 5 \cdot 5$, while the AGP antibody was diluted 1.0:13.2 with the dilution buffer. Before use, diluted antibody was mixed with reaction buffer (S2008; Dako) in the ratio 1:5, then passed through a $0.22 \mu \mathrm{m}$ membrane filter (SLGV 025NB; Millipore UK Ltd). Standards were prepared from a serum protein calibrator (X908; Dako): the range for the ACT assay was $0.05-1.20 \mathrm{~g} / 1$ and for the AGP assay $0 \cdot 1-3.0 \mathrm{~g} / \mathrm{l}$. The sample $(80 \mu \mathrm{l})$ was mixed with $250 \mu \mathrm{l}$ reagent for the ACT assay, while $20 \mu \mathrm{l}$ sample was mixed with $250 \mu \mathrm{l}$ reagent for the AGP assay, and analysed on a Cobas Fara centrifugal spectrophotometer (Hoffman La-Roche Ltd). Intra-batch CV for ACT and AGP were $3-8 \%$, while inter-assay $\mathrm{CV}$ were $6 \%$. 
The normal range for ACT in adult plasma is $0 \cdot 3-0.6 \mathrm{~g} / 1$ (Thompson et al. 1992). However, little data exist for sneonates, although Freer et al. (1979) have suggested a reference range of $0.05-0.48 \mathrm{~g} / \mathrm{l}$ for cord blood samples after 34-43 weeks of gestation. The adult reference range for AGP is $0.5-1.0 \mathrm{~g} / 1$ (Fiteau et al. 1993). For neonates, Sann et al. (1981) proposed a mean plasma AGP concentration of 0.18 (SD 0.08$) \mathrm{g} / \mathrm{l}$ for the first $2 \mathrm{~d}$ of life, rising to $0.52(\mathrm{SD} 0.08) \mathrm{g} / \mathrm{l}$ at $5-6 \mathrm{~d}$, then remaining constant up to 1 month. Viani et al. (1992) agreed with the earlier workers and recommended a range of $0 \cdot 14-0.50 \mathrm{~g} / \mathrm{l}$.

\section{Statistical analyses}

Data were analysed using the Statistical Package for Social Sciences (SPSS for Windows, version 9.0.0; SPSS Inc., Chicago, IL, USA). Data on fat-soluble vitamins, carotenoids and APP were skewed, and were therefore log-transformed to normalise the data and analysed using parametric statistics. Geometric mean values and interquartile ranges were calculated and used throughout. During descriptive analysis of the data, it was obvious that gestational age and birth weight might influence plasma retinol and the APP and their contribution was investigated using univariate ANOVA with Bonferroni post hoc tests. A test of homoscedasticity showed more negative residuals for the carotenoids and APP than would be expected in a normal distribution; therefore, the log-transformed data for these variables were used for correlation and regression analyses. In addition, partial correlations (which are indicated by $r_{12.3}$ ) were determined between each variable and retinol after controlling for the effects of age. Stepwise backward multiple regression analyses with retinol as the dependent variable was conducted to determine which variables best predicted plasma retinol concentrations in the neonates and included the following log-transformed independent variables: ACT, AGP, $\beta$-carotene, $\alpha$-carotene, lycopene, lutein, $\beta$-cryptoxanthin, $\alpha$-tocopherol, and non-log transformed variables: age, group, length and weight, mother's age, mother's education, mother's occupation, parity. Those variables not included in the table were not significant $(P>0.05)$.

\section{Results}

The mean age of the mothers was 28 years; $95 \%$ were married and $38 \%$ were having their first child. The largest group $(48 \%)$ was educated up to secondary level. Their occupations were varied: $28 \%$ were traders, $31 \%$ wageearners and $26 \%$ were professionally employed, while the rest were farmers, housewives or unemployed. Most of the subjects lived in urban areas. Mothers remained in hospital with their infants and feeding was on demand. Food was available for mothers within the hospital, but it was more usual for meals to be brought in for them from home; hence, many mothers continued eating their normal diet. No dietary intake records were kept. None of the mothers was given vitamin A supplements postpartum and none reported any symptoms of mastitis.

Blood samples were taken from 205 neonates, including sixteen sets of twins (in four of the sets only one twin survived). Complete biochemical and anthropometric data were available for 192 neonates; however, data on gestational age were missing for twenty-eight subjects, because the hospital case notes were lost. The mean age of the neonates at the time of the blood sample was 5.0 (SD 3.7) d. There were no differences between gender for weight, height, any of the micronutrients or APP. Therefore, data from males and females were combined for statistical analysis.

\section{Anthropometry}

The mean weight of the neonates was 2.6 (SD 0.70) $\mathrm{kg}$ and the mean length was 0.457 (SD 0.048) $\mathrm{m}$. However, fifty-six $(34 \%)$ of the neonates were premature with a mean gestational age of 33.2 (95\% CI 28.0, 36.0) weeks compared with 38.9 (95\% CI $37.0,42.6 ; n$ 108) weeks at full term. The mean weights and lengths of the premature infants were significantly smaller than those of infants of normal gestational age $(2.05 \mathrm{~kg}$ and $0.4258 \mathrm{~m} \mathrm{v.} 2.88 \mathrm{~kg}$ and $0.4692 \mathrm{~m}$ respectively; $P<0.0001$, ANOVA). Mean values for both the normal and premature infants were lower than the 50th centile on the Centres for Disease Control and Prevention (2000) paediatric growth charts $(3.4 \mathrm{~kg}$ and $0.480 \mathrm{~m}$ for girls and $3.5 \mathrm{~kg}$ and $0.495 \mathrm{~m}$ for boys). Sixty-seven $(35 \%)$ of the neonates were $<2.5 \mathrm{~kg}$ and were classified as low-birth-weight infants; fortythree $(64 \%)$ of these were also premature. There was no relationship between mothers' education or occupation and birth weights (results not shown).

\section{Relationships with age}

Table 1 shows the geometric mean values of retinol, carotenoids and APP, the inter-quartile ranges (25th and 75th centiles) and, as a measure of variance, a value termed the geometric standard error. The Pearson correlation coefficient shows the relationship between each variable and age. All carotenoids and retinol showed positive correlations with age, but the APP did not.

\section{Inter-relationships of retinol, gestational age and birth weight}

The distribution of high and low retinol values according to gestational age and weight is shown in Table 2 . The infants were divided into four groups defined as follows: normal gestational age $(\geq 37$ weeks) and normal weight $(\geq 2.5 \mathrm{~kg}$ ) (group 1); normal weight and premature $(\leq 36$ weeks) (group 2); low weight $(<2.5 \mathrm{~kg}$ ) and normal gestational age (group 3); low weight and premature (group 4). Overall, neonates who had low weights had significantly lower mean plasma retinol concentrations than those whose weights were in the normal range $(0.46 v$. $0.59 \mu \mathrm{mol} / \mathrm{l}$ respectively; $P<0.003$, ANOVA). In addition, babies who were both premature and had body weight $<2.5 \mathrm{~kg}$ had significantly lower mean plasma retinol concentrations than those of normal gestational age and weight $(0.45$ v. $0.59 \mu \mathrm{mol} / 1$ respectively; $P<0.023$, univariate ANOVA; $P=0.008$, post hoc Bonferroni test). If age (d after birth) and two new variables, birth-weight 
Table 1. Plasma concentration of retinol, carotenoids, $\alpha$-tocopherol and acute-phase proteins in Nigerian neonates and the association of age with these variablest

\begin{tabular}{|c|c|c|c|c|c|c|}
\hline \multirow[b]{2}{*}{ Variable } & \multirow[b]{2}{*}{$n$} & \multicolumn{2}{|c|}{ Geometric } & \multicolumn{2}{|c|}{ Inter-quartile range } & \multirow{2}{*}{$\begin{array}{l}\text { Pearson correlation } \\
\text { coefficient with age }\end{array}$} \\
\hline & & Mean‡ & SE§ & 25th & 75th & \\
\hline Retinol $(\mu \mathrm{mol} / \mathrm{l})$ & 192 & 0.538 & 0.020 & 0.386 & 0.735 & $0 \cdot 238^{\star *}$ \\
\hline$\alpha$-Carotene $(\mu \mathrm{mol} / \mathrm{l})$ & 192 & 0.072 & 0.010 & 0.041 & 0.249 & $0.211^{\star \star}$ \\
\hline B-Carotene $(\mu \mathrm{mol} / \mathrm{l})$ & 192 & 0.076 & $0 \cdot 11$ & 0.033 & 0.281 & $0 \cdot 247^{\star \star}$ \\
\hline B-Cryptoxanthin ( $\mu \mathrm{mol} / \mathrm{l})$ & 192 & 0.014 & 0.003 & 0.008 & 0.065 & $0.217^{\star \star}$ \\
\hline Lutein $(\mu \mathrm{mol} / \mathrm{l})$ & 192 & 0.080 & 0.060 & 0.043 & 0.178 & $0.223^{\star *}$ \\
\hline $\operatorname{ACT}(g / l)$ & 192 & 0.37 & 0.016 & 0.280 & 0.510 & 0.103 \\
\hline AGP $(g / l)$ & 192 & 0.60 & 0.030 & 0.410 & 0.995 & 0.083 \\
\hline
\end{tabular}

ACT, $\alpha_{1}$-antichymotrypsin; AGP, $\alpha_{1}$-acid glycoprotein.

** $P<0.01$.

†For details of subjects and procedures, see p. 354

$\mp$ Geometric mean value.

$\S$ As a measure of variance the value termed the geometric standard error is calculated as: (antilog (mean + standard error of logged values) - geometric mean).

group (low birth weight or normal weight) and gestational group (premature or normal gestation), are put into a univariate general linear model, only age and birthweight group had a significant effect on plasma retinol concentration $(P<0.002$ v. $P<0.05$ respectively $)$. There was no interaction between age, birth weight or gestational group.

Inter-relationships of the acute-phase proteins, retinol, gestational age and birth weight

Thirty-two neonates (17\%) had abnormal ACT values $(>0.60 \mathrm{~g} / \mathrm{l})$ and forty-four $(23 \%)$ had abnormal AGP values $(>1.0 \mathrm{~g} / \mathrm{l})$. AGP was correlated with weight and length ( $r 0 \cdot 16, P=0.025$ and $r 0.24, P=0.001$ respectively), but ACT did not. The majority of neonates with high APP were in the group with normal weight and gestational age (ACT $44 \%$, AGP 52\%) (Table 3). APP was not correlated with any of the carotenoids (results not shown) or age. ACT and AGP strongly correlated with each other ( $r$ 0.784, $P<0.0001$ ). Both ACT and AGP correlated weakly with plasma retinol (ACT $r 0.18, P=0.009$; AGP $r 0.15, P=0.039)$ and in both cases the relationship was positive. Only AGP correlated with birth weight $(r 0 \cdot 232, P=0 \cdot 004)$. Elevated concentrations of both APP showed skewed distributions with age, since 59\% (AGP, twenty-six of forty-four subjects) and $63 \%$ (ACT, twenty of thirty-two subjects) of all raised values were in infants $<6 \mathrm{~d}$ old. That is, there were more high values in the younger infants. Sann et al. (1981) reported that plasma AGP concentrations rose to a peak at 5 to $6 \mathrm{~d}$ old in healthy full-term neonates; therefore, the Nigerian data were examined separately above and below this age. Of children $<6 \mathrm{~d}$ old, $76 \%$ (ninety-six of 126 subjects) had low plasma retinol results $(<0.7 \mu \mathrm{mol} / \mathrm{l})$ and, in this subgroup, the relationship with APP was positive (ACT $r$ 0.34, $P<0.0001$, results not shown; AGP $r 0.313, P<0.0001$, $n$ 126, Fig. 1). The proportion of low plasma retinol concentrations $(<0.7 \mu \mathrm{mol} / \mathrm{l})$ in those neonates $\geq 6 \mathrm{~d}$ was $62 \%$ (forty-one of sixty-six subjects) and the relationships with both APP were negative (ACT $r-0.28, P=0.022$, results not shown; AGP $r-0 \cdot 29, P=0 \cdot 018, n$ 66, Fig. 2).

\section{Statistical relationships}

Table 4 describes the correlations among all variables with plasma retinol and with age. Weight and length, all the carotenoids, AGP, ACT and age were significantly positively correlated with retinol. There were strong positive relationships between age and the carotenoids (Table 1).

Table 2. Distribution of retinol concentrations ( $\mu \mathrm{mol} / \mathrm{l})$ according to gestational group and weight†‡

(Geometric mean values and $95 \%$ confidence intervals)

\begin{tabular}{|c|c|c|c|c|c|}
\hline & \multicolumn{2}{|c|}{ Normal weight§ } & \multicolumn{2}{|c|}{ Low weight§ } & \multirow[b]{2}{*}{ All groups } \\
\hline & Normal gestation (group 1)\| & Premature (group 2)\| & Normal gestation (group 3)\| & Premature (group 4)\| & \\
\hline Mean & $0.59^{a}$ & $0.53^{\mathrm{ab}}$ & $0.49^{\mathrm{ab}}$ & $0.45^{\mathrm{b}}$ & 0.53 \\
\hline $95 \% \mathrm{Cl}$ & $0.22,1.32$ & $0.28,1.02$ & $0.14,1.06$ & $0.15,0.94$ & $0.24,1.08$ \\
\hline & & 13 & 19 & 43 & 164 \\
\hline Mean value & \multirow{3}{*}{\multicolumn{2}{|c|}{$\begin{array}{c}0.59 \\
0.24,1.33 \\
125\end{array}$}} & \multirow{2}{*}{\multicolumn{2}{|c|}{$\begin{array}{c}0.46^{\star} \\
0.14,0.99\end{array}$}} & \\
\hline $95 \% \mathrm{Cl}$ & & & & & \\
\hline$n$ & & 125 & \multicolumn{2}{|c|}{67} & \\
\hline
\end{tabular}

\footnotetext{
${ }^{a, b}$ Mean values within a row with unlike superscript letters were significantly different (univariate ANOVA, $P<0.023 ;$ post hoc Bonferroni, $P<0.008$ ). Mean value was significantly different from that of normal weight neonates (ANOVA): ${ }^{*} P<0.003$.

† For details of subjects and procedures, see p. 354

$\ddagger$ Where gestational age was used in the analysis, data were only available for 164 neonates as the gestational ages of twenty-eight neonates were not recorded. $\S$ Normal weight $\geq 2.5 \mathrm{~kg}$, low weight $<2.5 \mathrm{~kg}$.

|| Normal gestational age $\geq 37$ weeks, premature gestational age $\leq 36$ weeks.
} 
Table 3. Distribution of elevated and normal concentrations of $\alpha$-antichymotrypsin (ACT) and $\alpha_{1}$-acid glycoprotein (AGP) according to gestational age and weight*

(Geometric mean values and $95 \%$ confidence intervals)

\begin{tabular}{|c|c|c|c|c|c|c|c|c|c|c|c|c|c|c|c|}
\hline & \multicolumn{6}{|c|}{ Normal weight† } & \multicolumn{6}{|c|}{ Low weight† } & \multirow{2}{*}{\multicolumn{3}{|c|}{ All groups§ }} \\
\hline & \multicolumn{3}{|c|}{$\begin{array}{l}\text { Normal gestation } \\
\quad \text { (group 1) } \ddagger\end{array}$} & \multicolumn{3}{|c|}{$\begin{array}{l}\text { Premature } \\
\text { (group 2) } \ddagger\end{array}$} & \multicolumn{3}{|c|}{$\begin{array}{l}\text { Normal gestation } \\
\quad \text { (group } 3) \ddagger\end{array}$} & \multicolumn{3}{|c|}{$\begin{array}{l}\text { Premature } \\
\text { (group 4) } \ddagger\end{array}$} & & & \\
\hline & Mean & $95 \% \mathrm{Cl}$ & $n$ & Mean & $95 \% \mathrm{Cl}$ & $n$ & Mean & $95 \% \mathrm{Cl}$ & $n$ & Mean & $95 \% \mathrm{Cl}$ & $n$ & Mean & $95 \% \mathrm{Cl}$ & $n$ \\
\hline $\mathrm{ACT} \leq 0.6 \mathrm{~g} / \mathrm{l}$ & 0.33 & $0.17,0.54$ & 75 & 0.31 & $0.16,0.46$ & 11 & 0.32 & $0.08,0.60$ & 17 & 0.32 & $0.18,0.57$ & 36 & 0.32 & $0.17,0.56$ & 160 \\
\hline ACT $>0.6 \mathrm{~g} / \|$ & 0.82 & $0.63,1.09$ & 14 & 0.85 & $0.76,0.949$ & 2 & 0.65 & $0.62,0.679$ & 2 & 0.95 & $0.70,1 \cdot 15$ & 7 & 0.82 & $0.63,1.27$ & 32 \\
\hline$A G P>1.0 \mathrm{~g} / \mathrm{l} \|$ & $1 \cdot 30$ & $0.98,2.84$ & 23 & $1 \cdot 22$ & $1.05,2.039$ & 3 & $1 \cdot 34$ & $1.11,1.790$ & 3 & $1 \cdot 28$ & $1 \cdot 03,2 \cdot 61$ & 6 & $1 \cdot 36$ & $1.00,2.89$ & 44 \\
\hline
\end{tabular}

${ }^{*}$ For details of subjects and procedures, see p. 354.

$\dagger$ Normal weight $\geq 2.5 \mathrm{~kg}$, low weight $<2.5 \mathrm{~kg}$.

$\ddagger$ Normal gestational age $\geq 37$ weeks, premature gestational age $\leq 36$ weeks.

$\S$ Where gestational age was used in the analysis, data were only available for 164 neonates as the gestational ages of twenty-eight neonates were not recorded;

therefore, numbers shown in the 'all groups' are greater than the sum of the four columns.

\| Concentrations of ACT $>0.6 \mathrm{~g} / \mathrm{l}$ and AGP $>1.0 \mathrm{~g} / \mathrm{l}$ are above normal adult range.

I Maximum and minimum values are given because of low numbers in the group.

Further partial correlations $\left(r_{12.3}\right)$ between each variable and retinol were recalculated after controlling for the effects of age. All the carotenoids, weight and ACT were still significantly positively correlated with retinol but AGP was not.

A multiple regression analysis was then conducted to determine which variables best predicted plasma retinol concentration in the neonates (Table 5). The results suggest

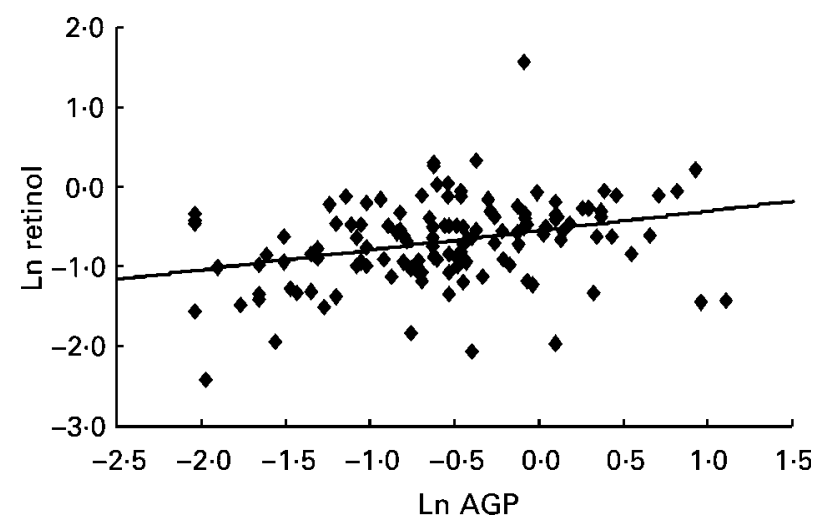

Fig. 1. Relationship between log retinol and $\log \alpha_{1}$-acid glycoprotein (AGP) in Nigerian neonates age $<6 \mathrm{~d}(r 0.313, P=0.0001)$. For details of subjects and procedures, see p. 354 .

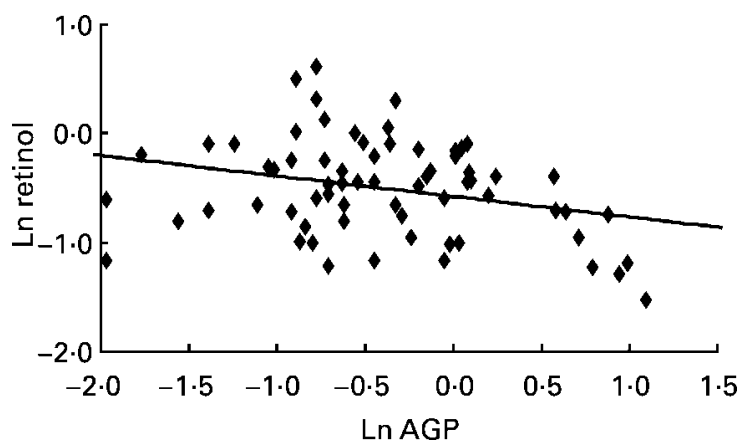

Fig. 2. Relationship between log retinol and $\log \alpha_{1}$-acid glycoprotein (AGP) in Nigerian neonates age $\geq 6 \mathrm{~d}(r 0.289, P=0.018)$. For details of subjects and procedures, see p. 354 . that plasma lutein is most strongly related to plasma retinol $(P=0.0001)$ together with weight $(P=0.001)$, age $(P=0.001)$ and ACT $(P=0.021)$, which jointly explained $30 \%$ of the variance. The prediction equation based on Table 5 is:

predicted value for $\log$ retinol

$$
\begin{aligned}
= & -0.679+0.178(\text { weight })+0.172(\log \text { ACT }) \\
& +0.165(\log \text { lutein })+0.037(\text { age }) .
\end{aligned}
$$

Although the relationship between plasma retinol and the APP was not typical of that seen when inflammation is associated with depressed plasma retinol, the possible effect of inflammation on retinol was quantified using the results described by Paracha et al. (2000). The results of Paracha et al. (2000) were based on infants $<5$ years of age, but a subsequent meta-analysis of fifteen studies confirmed the depressing effect of infection on retinol and proposed such a correction be performed on data for all age groups (Thurnham et al. 2002). Paracha et al. (2000) showed that if both ACT and AGP were above

Table 4. Correlation matrix describing relationships with retinol and

\begin{tabular}{|c|c|c|}
\hline & Retinol & $\begin{array}{l}\text { Retinol with effect of } \\
\text { age removed }\left(r_{12.3}\right)\end{array}$ \\
\hline Age & $0.238^{\star \star}$ & \\
\hline Weight & $0.204^{\star *}$ & $0 \cdot 259^{\star}$ \\
\hline Length & $0.142^{*}$ & $0.180^{\star}$ \\
\hline$\alpha$-Carotene & $0.352^{\star \star}$ & $0 \cdot 321^{\star \star}$ \\
\hline B-Carotene & $0.337^{* *}$ & $0 \cdot 298^{\star \star}$ \\
\hline B-Cryptoxanthin & $0.388^{\star \star}$ & $0.357^{\star \star}$ \\
\hline Lutein & $0.414^{\star *}$ & $0.384^{\star \star}$ \\
\hline Lycopene & $0.260^{* *}$ & $0 \cdot 224^{\star \star}$ \\
\hline ACT & $0.186^{\star}$ & $0.175^{\star}$ \\
\hline AGP & $0 \cdot 148^{*}$ & 0.132 \\
\hline
\end{tabular}
with retinol after controlling for age

ACT, $\alpha$-antichymotrypsin; AGT, $\alpha_{1}$-acid glycoprotein.

${ }^{\star} P<0.05,{ }^{* \star} P<0.01$.

†For details of subjects ( $n$ 192)and procedures, see p. 354 
Table 5. Multiple stepwise regression equation with retinol as the dependent variable ${ }^{\star} \dagger$

\begin{tabular}{lcccc}
\hline $\begin{array}{l}\text { Dependent and } \\
\text { independent variables }\end{array}$ & B & SE B & B & $\begin{array}{c}\text { Statistical } \\
\text { significance }\end{array}$ \\
\hline Constant & -0.679 & 0.201 & & 0.001 \\
Weight & 0.178 & 0.053 & 0.237 & 0.001 \\
ACT & 0.172 & 0.074 & 0.163 & 0.021 \\
Lutein & 0.165 & 0.034 & 0.348 & 0.0001 \\
Age & 0.0371 & 0.011 & 0.250 & 0.001 \\
\hline
\end{tabular}

ACT, $\alpha_{1}$-antichymotrypsin.

* For details of subjects $(n 164)$ and procedures, see p. 354 and Table 2.

†Stepwise backward multiple regression analyses with retinol as the dependent variable included the following log-transformed independent variables: ACT, $\alpha_{1}$-acid glycoprotein, $\beta$-carotene, $\alpha$-carotene, lycopene, lutein, ß-cryptoxanthin and $\alpha$-tocopherol, and non-log transformed variables: age, premature or not, low birth weight or not, length and weight, mother's age, mother's education, mother's occupation and parity. Those variables not included in the Table were not significant $(P>0.05)$.

normal, plasma retinol was depressed by $0.24 \mathrm{~mol} / \mathrm{l}$, whereas if only one APP was elevated, plasma retinol was only depressed by $0 \cdot 10 \mathrm{~mol} / \mathrm{l}$. Table 6 shows the corrected retinol values for those neonates with elevated APP. Fifty-three children had elevated APP and correcting the retinol concentrations increased the mean value for this group of children from a value less than the threshold plasma retinol of $0.7 \mu \mathrm{mol} / \mathrm{l}$ to one that was $>0.7 \mu \mathrm{mol} / \mathrm{l}$. In addition when the transient depression in plasma retinol produced by the sub-clinical infection was corrected in the most at risk group, i.e. those with plasma retinol concentrations $<0.35 \mu \mathrm{mol} / \mathrm{l}(n$ 35), $21 \%$ of these neonates moved from the high- to the low-risk group. The effect on mean plasma retinol for the whole group of neonates, however, was small, with an increase from 0.56 to $0.61 \mu \mathrm{mol} / \mathrm{l}$.

\section{Discussion}

From the time of conception until delivery, the health of the fetus is dependent upon the health of the mother. Maternal health is influenced by socio-economic and nutritional status before and during pregnancy and the lack and/ or excess of individual nutrients may have harmful effects on the development of the fetus (Wahid \& Shadia, 1987). Fetal plasma vitamin A concentrations tend to be lower than maternal concentrations and evidence suggests that the maternal:fetal concentrations of plasma vitamin $\mathrm{A}$ in healthy human pregnancies is approximately 2:1 (King, 1982). Vitamin A is transferred to the fetus during the last trimester of pregnancy and there is thought to be an association between low birth weight and low concentrations of maternal retinol (King, 1982).

The geometric mean value of plasma retinol for fullterm Nigerian neonates in the present study was $0.57 \mu \mathrm{mol} / 1$, which was low compared with a number of other studies: $0.84 \mu \mathrm{mol} / \mathrm{l}$ in the USA (Shenai et al. 1981), $0.71 \mu \mathrm{mol} / 1$ in the UK (Chan et al. 1993) and $0.74 \mu \mathrm{mol} / \mathrm{l}$ in Egypt (Hussein \& Ali, 2000). Even greater values were reported by Basu et al. (1994) and Cardonoparez et al. (1996) for full-term neonates in Canada, namely 1.23 and 1.38 (range $0.70-2.50$ ) $\mu \mathrm{mol} / \mathrm{l}$ respectively; Godel et al. (1996) postulated that values between 0.7 and $2.5 \mu \mathrm{mol} / 1$ represented a 'normal' range for newborn infants. However, this range appears to include some unusually high values, since the ranges of retinol concentrations reported by the other workers were similar to those reported by Chan et al. (1993), namely $0 \cdot 34-1.27 \mu \mathrm{mol} / \mathrm{l}$. Blood samples were taken from the neonates in our present study between 1 and $20 \mathrm{~d}$ postnatally and the plasma was stored for up to 9 months at $-50^{\circ} \mathrm{C}$ and subsequently at $-70^{\circ} \mathrm{C}$ for up to 6 months. However, we do not think that our retinol concentrations were low due to storage conditions, as work by Craft et al. (1988) has shown that plasma carotenoids and retinol were stable for at least 28 months when stored at $-70^{\circ} \mathrm{C}$. In addition, plasma retinol concentrations were not significantly different even when stored at $-20^{\circ} \mathrm{C}$ for 15 months, although carotenoid concentrations were significantly less $(P<0.05)$ compared with plasma stored at $-70^{\circ} \mathrm{C}$. Our current samples were stored in small tightly stoppered tubes to reduce the possibility of dehydration and at temperatures of not more than $-50^{\circ} \mathrm{C}$, hence should have remained stable for at least 18 months. Therefore, the overall conclusion from the comparisons with other studies is that the mean retinol concentration was lower than would have been expected for full-term healthy neonates.

Both the premature and low-birth-weight Nigerian neonates had mean plasma retinol concentrations of $0.46 \mu \mathrm{mol} / 1$ and this value was comparable with that reported for South African low-birth-weight and premature infants $(0.45 \mu \mathrm{mol} / 1$; Coutsoudis et al. 2000). However,

Table 6. Correction of plasma retinol where acute-phase proteins are elevated*

(Geometric mean values and $95 \%$ confidence intervals)

\begin{tabular}{|c|c|c|c|c|c|}
\hline \multirow[b]{2}{*}{ Inflammatory state represented by APP (g/l) } & \multirow[b]{2}{*}{$n$} & \multicolumn{2}{|c|}{ Uncorrected retinol $(\mu \mathrm{mol} / \mathrm{l})$} & \multicolumn{2}{|c|}{ Corrected retinol $(\mu \mathrm{mol} / \mathrm{l}) \dagger$} \\
\hline & & Mean & $95 \% \mathrm{Cl}$ & Mean & $95 \% \mathrm{Cl}$ \\
\hline$A C T>0.6+A G P>1.0$ & 23 & 0.54 & $0 \cdot 22,1 \cdot 14$ & 0.80 & $0.46,1.41$ \\
\hline$A C T>0.6+A G P \leq 1.0$ & 9 & 0.69 & $0.31,0.94$ & 0.79 & $0.41,1.16$ \\
\hline$A C T \leq 0.6+A G P>1.0$ & 21 & 0.65 & $0.15,0.94$ & 0.71 & $0.24,0.96$ \\
\hline No elevated APP, i.e. healthy subjects & 139 & 0.54 & $0.23,1.33$ & & \\
\hline All subjects & 192 & 0.56 & $0.24,1 \cdot 17$ & 0.61 & $0.25,1.17$ \\
\hline
\end{tabular}

ACT, $\alpha_{1}$-antichymotrypsin; AGP, $\alpha_{1}$-acid glycoprotein; APP, acute-phase protein

* For details of subjects and procedures, see p. 354

†Based on the relationship between plasma retinol and APP, plasma retinol was corrected for the presence of sub-clinical infection (Paracha et al. 2000): where ACT $(>0.6 \mathrm{~g} / \mathrm{l})$ and AGP $(>1.0 \mathrm{~g} / \mathrm{l})$ are elevated, $0.24 \mu \mathrm{mol} / \mathrm{l}$ is added to plasma retinol value. Where ACT or AGP are elevated, $0.1 \mu \mathrm{mol} / \mathrm{l}$ is added to plasma retinol value. 
the mean values were low compared with other studies, e.g. preterm US infants $(0.56 \mu \mathrm{mol} / \mathrm{l}$; Shenai et al. 1981) and preterm Egyptian infants $(0.65 \mu \mathrm{mol} / \mathrm{l}$; Hussein \& Ali, 2000). Furthermore, Shenai et al. (1981) concluded that plasma retinol concentrations $<0.57 \mu \mathrm{mol} / \mathrm{l}$ in 1 -d-old premature infants indicated vitamin A depletion. Low weight, particularly if coupled with prematurity, has been found to be associated with lower retinol concentrations and in the present study we found a significant correlation between plasma retinol and gestational age even after including the effect of the neonates' age (i.e. age at which the plasma sample taken) in the analysis. Chan et al. (1993) also found a correlation between vitamin A concentration and gestational age and suggested gestational age must be taken into account when interpreting vitamin A levels.

The question under consideration was to what extent low plasma retinol values represented inadequate maternal nutrition or the consequences of infection or trauma. In the present study $71 \%$ of the neonates had retinol values $<0.70 \mu \mathrm{mol} / 1$ and $18 \%$ of these had potentially severe VAD $(<0.35 \mu \mathrm{mol} / \mathrm{l})$, suggesting that vitamin A status was poor in many of the neonates. Several factors may affect the transport of vitamin A to the fetus: inadequate maternal stores of vitamin A, impaired transport of retinol across the placenta (Rosso, 1990; Bluhm et al. 1994; Rondo et al. 1995), impaired mobilisation of vitamin A from the maternal liver (as a result of reduced synthesis of retinol-binding protein due to infection or deficiencies of vitamin $\mathrm{A}$ or $\mathrm{Zn}$ ), or decreased circulating maternal plasma retinol (as a result of maternal infection or deficiency). Likewise, low levels of the plasma vitamin A transport proteins retinol-binding protein and transthyretin in the newborn infant will depress plasma vitamin A (Surks \& Oppenheimer, 1964; Kanai et al. 1968; Smith \& Goodman, 1971; Goodman, 1984). Studies have also shown that immaturity of hepatic production of retinolbinding protein may be a factor responsible for low plasma levels of vitamin A in newborn infants (Valquist et al. 1975; Shenai, 1989).

Neither maternal nor infant plasma retinol-binding protein were measured in the present study as there was only a small amount of plasma, but two APP, ACT and AGP, were measured. ACT and AGP are useful markers of sub-clinical or chronic infection (Thompson et al. 1992). Plasma concentrations of ACT are known to increase rapidly in the first few hours following exposure to infection and reach a maximum at $24 \mathrm{~h}$, while AGP rises more slowly reaching a maximum at $48-72 \mathrm{~h}$ (Calvin \& Price, 1986). Once the clinical stage of the infection subsides, ACT decreases more rapidly than AGP (Fleck, 1989). In addition, AGP has been shown to be a good indicator of bacterial disease (Fleck \& Myers, 1985) and is certainly capable of responding to infection in neonates, as shown by Philip \& Hewitt (1983), where mean values of 0.26 (SEM 0.01) and 0.81 (SEM 0.01) g/l were obtained in uninfected and infected neonates respectively. Alt et al. (1984) also found slightly higher concentrations of AGP in neonates with materno-fetal infection $(0.56$ (SEM 0.003) g/l). Twenty-three percent of the Nigerian neonates had AGP concentrations $>1.0 \mathrm{~g} / \mathrm{l}$ suggestive of exposure to infection post-natally or in utero.
In our present study, the median ACT concentration was $0.37 \mathrm{~g} / \mathrm{l}$ and only ACT contributed significantly to the variance in plasma retinol in the multiple linear regression analysis $\left(r^{2} 3 \%\right)$. Very little data on ACT concentrations in neonates exist, and the only reference quotes a mean concentration in cord blood of 0.22 (range $0.05-$ 0.48) $\mathrm{g} / \mathrm{l}$ from eighty-one infants delivered after 34-43 weeks of gestation (Freer et al. 1979). However, more work has been done on plasma AGP in neonates and the strong correlation between AGP and ACT in the infant plasma suggests that the two proteins are controlled by similar processes. Median AGP $(0.60 \mathrm{~g} / \mathrm{l})$ values in the Nigerian infants were within the accepted normal ranges for adults $(0.5-1.0 \mathrm{~g} / \mathrm{l})$, but possibly outside the normal neonatal range $(0 \cdot 14-0.50 \mathrm{~g} / \mathrm{l})$ suggested by Viani et al. (1992). Nevertheless, the proportion with sub-clinical infection may well have been underestimated because of immaturity of APP synthesis in the livers of Nigerian neonates. Sann et al. (1981) reported that healthy neonates at full-term had plasma AGP concentrations of 0.18 (SD $0.08) \mathrm{g} / \mathrm{l}$ for the first $2 \mathrm{~d}$, rising to 0.52 (SD 0.08) $\mathrm{g} / \mathrm{l}$ at $5-$ $6 \mathrm{~d}$ of life, then remaining constant for up to 1 month. This observation may explain the positive association between plasma retinol and both APP in those infants $<6 \mathrm{~d}$ of age (Fig. 1). However, the Nigerian infants were all apparently healthy; therefore, the positive correlations with the APP observed during days 1-5 were probably due to the increasing plasma retinol from the maternal milk and a coincidental increasing capacity to synthesise APP, which peaked at about $5 \mathrm{~d}$. Subsequently, the negative correlations shown in Fig. 2 (day 6 onwards) reflected the continuing increase in plasma retinol, but no further increase in APP. An underestimation of sub-clinical infection may be the reason why attempts to correct plasma retinol using the procedure outlined by Paracha et al. (2000) made almost no difference to the mean retinol value for the group.

Infants are born with very low reserves of vitamin A and are dependent on milk for their supply in the early months of life. The cross-sectional data suggest that plasma retinol and the carotenoid concentrations were increasing steadily during the period of development $(0-20 \mathrm{~d})$ and, for the majority, the source of vitamin A was breast-milk. Milk provides both pre-formed retinol, as well as carotenoids and pro-vitamin A carotenes. All infant plasma carotenoid concentrations correlated individually with retinol and with age, and the correlations with age suggest that the breastmilk was supplying an adequate amount of these nutrients. In the multiple linear regression, lutein was singularly the most important carotenoid in explaining neonatal plasma retinol. The association between lutein and retinol in the neonates suggests that a significant proportion of the increase in retinol was derived from green vegetable sources. B-Carotene is the main source of vitamin $A$ in vegetables, but an unknown amount of B-carotene will be converted to retinol during absorption. Lutein is also present in most leafy green vegetables and in approximately equal amounts to B-carotene (Thurnham et al. 1997). Lutein is not a pro-vitamin A carotenoid and, as far as is known, there is far less metabolism of non-pro-vitamin A carotenoids than pro-vitamin A carotenes. Thus, because 
lutein is consumed at the same time as B-carotene, when vegetables are consumed, it is a useful surrogate marker for the intake of $\beta$-carotene.

The relationship between lutein and retinol in the Nigerian neonates may nevertheless be considered surprising since the major source of the B-carotene for many, if not all, of the mothers in this community will have been red palm oil, which contains very little (if any) lutein. However, we have previously reported a close correlation between increases in plasma concentrations of retinol and lutein in Pakistani infants (mean age 10-14 months) at a time when there was a seasonal increase in the availability of fruits and vegetables (Thurnham et al. 1997). Furthermore, we have shown that concentrations of plasma lutein in Irish neonates correlate with maternal plasma lutein at birth; thus, maternal vegetable intake during gestation influences neonatal lutein values (Jewell et al. 2000). In addition, the major dietary source of vitamin A for both the Nigerian neonates and the Pakistani infants was mothers' milk. Jewell et al. (2000) and others (Khachik et al. 1997) have shown that the concentration of lutein in breast milk is often higher than B-carotene. Hence, the provision of lutein is strongly linked to the maternal intake of fruits and vegetables, and this may be the reason for the strongest correlation of the biomarkers examined in the breast-fed infants being between lutein and retinol.

In conclusion, weights and lengths, and plasma retinol, were low in the neonates and may have been a consequence of poor maternal nutrition. We suggest that the unexpected positive correlation between the APP and plasma retinol in neonates in days $1-5$ inclusive might have been a consequence of the increasing hepatic synthetic capacity to produce APP and a steady increase in plasma retinol from breast-milk over the period. The cross-sectional data suggest the concentration of retinol increased rapidly following birth and was more strongly linked with nutrition than with the presence of infection. The small number of neonates with elevated APP levels may reflect the trauma of birth, but these had only a minimal influence on plasma retinol in contrast to dietary factors like lutein, a surrogate marker of vitamin A nutrition.

In Nigeria and other populations where VAD is an important public health problem, we suggest prophylactic vitamin A supplements should be given to infants and preschool children (0-59 months) and pregnant and postpartum women according to the new World Health Organization recommendations (Ross, 2002). In addition, where possible a programme of nutritional and health education should be given to schoolchildren and to all pregnant women. However, as there is very little antenatal care, specific education to pregnant mothers is currently not possible.

\section{Acknowledgements}

The study was supported in part by research grant no. 1427DT from the University Research Committee of Obafemi Awolowo University, Ile-Ife. Nigeria. We also acknowledge the cooperation of parents of the study subjects.

\section{References}

Adelekan DA, Fatusi AO, Fakunle JB, Olotu CT, Olukoga IA, Jinadu MK \& Ojofeitimi EO (1997) Prevalence of malnutrition and vitamin A deficiency in Nigerian pre-school children subsisting on high intakes of carotenes. Nutr Health 12, 1724.

Adelekan DA, Owa JA, Chan W, et al. (2002) Plasma retinol, carotenoids and acute phase proteins in Nigerian neonates. J Nutr 132, 2971S.

Alt R, Erny P, Messer J \& Willard D (1984) Neonatal bacterial infections. Kinetic study of C-reactive protein and orosomucoid. Presse Med 13, 1373-1376.

Basu TK, Wein EE, Gangopadhyay KC, Wolever TMS \& Godel JC (1994) Plasma vitamin A (retinol) and retinol binding protein in new-borns and their mothers. Nutr Res 14, 1297-1303.

Bluhm DP, Summers RS \& Ellis JB (1994) Severe vitamin A deficiency in black neonates in a tertiary referral hospital in South Africa. J Trop Paediatr 40, 116-118.

Calvin J \& Price CP (1986) Measurement of serum $\alpha_{1}$-antichymotrypsin by immunoturbidometry. Ann Clin Biochem 23, 206-209.

Cardonoparez A, Valdesramos R, Topetelezama B, Mezacamacho C \& Udaetamora E (1996) Cord blood retinol and retinol binding protein in preterm and term neonates. Nutr Res 16, 191-196.

Centres for Disease Control and Prevention (2000) Pediatric growth charts. http://www.cdc.gov/growthcharts

Chan V, Greenough A, Cheeseman P \& Gamsu HR (1993) Vitamin A status in preterm and term infants at birth. $J$ Perinat Med 21, 59-62.

Coutsoudis A, Adhikarim M \& Coovadia HM (1995) Serum vitamin-A (retinol) concentrations and association with respiratory disease in premature infants. J Trop Pediatr 41, 230-233.

Coutsoudis A, Adhikarim M, Pillay K, Kuhn L \& Coovadia HM (2000) Effect of vitamin A supplementation on morbidity of low-birth-weight neonates. S Afr Med J 90, 730-736.

Craft NE, Brown ED \& Smith J (1988) Effects of storage and handling conditions on concentrations of individual carotenoids, retinol and tocopherol in plasma. Clin Chem 34, 44-48.

Fiteau SM, Morris SS, Abbott RA, et al. (1993) Influence of morbidity on serum retinol of children in a community-based study in northern Ghana. Am J Clin Nutr 58, 192-197.

Filteau SM, Morris SS, Raynes JG, et al. (1995) Vitamin A supplementation, morbidity, and serum acute-phase proteins in young Ghanaian children. Am J Clin Nutr 62, 432-438.

Fleck A (1989) Clinical and nutritional aspects of changes in acute-phase proteins during inflammation. Proc Nutr Soc 48, $347-354$

Fleck A \& Myers MA (1985) Diagnostic and prognostic significance of the acute-phase proteins. In The Acute-Phase Response to Injury and Infection, pp. 249-271 [AH Gordon and A Koj, editors]. Amsterdam: Elsevier Science Publishers $\mathrm{BV}$.

Freer DE, Statland BE, Johnson M \& Felton H (1979) Reference values for selected enzyme activities and protein concentrations in serum and plasma derived from cord-blood specimens. Clin Chem 25, 565-569.

Godel JC, Basu TK, Pabst HF, Hodges RS, Hodges PE \& $\mathrm{Ng}$ ML (1996) Perinatal vitamin A (retinol) status of Northern Canadian mothers and their infants. Biol Neonat 69, 133-139.

Goodman DW (1984) Vitamin A and retinoids in health and disease. New Eng J Med 310, 1023-1031. 
Hussein L \& Ali M (2000) Cord plasma retinol level and its impact on birth weight and growth velocity in infancy. Nutr Res 20, 1361-1366.

Jewell VC, Sweet D, Tubman R, Northrop-Clewes CA \& Thurnham DI (2000) Lutein and zeaxanthin levels in newborns and mothers. Proc Nutr Soc 59, 47A.

Kanai M, Raz A \& Goodman DW (1968) Retinol-binding protein: the transport protein for vitamin A in human plasma. J Clin Invest 47, 2025-2044.

Khachik F, Spangler CJ, Smith JCJ, Canfield LM, Steck A \& Pfander H (1997) Identification, quantification, and relative concentrations of carotenoids and their metabolites in human milk and serum. Ann Chem 69, 1873-1881.

King JC (1982) Vitamin requirements during pregnancy. In Nutrition in Pregnancy. Proceedings of the Tenth Study Group of the Royal College of Obstetricians and Gynaecologists, pp. 33-45 [DM Campbell and MDG Gillmer, editors]. London: Royal College of Obstetricians and Gynaecologists.

Paracha PI, Jamil A, Northrop-Clewes CA \& Thurnham DI (2000) Interpretation of vitamin A status in apparently healthy Pakistani children by using markers of subclinical infection. Am J Clin Nutr 72, 1164-1169.

Philip AG \& Hewitt JR (1983) Alpha 1-acid glycoprotein in the neonate with and without infection. Biol Neonat 43, 118-124.

Rondo PHC, Abbott R, Rodrigues LC \& Tomkins AM (1995) Vitamin A, folate and iron concentrations in cord and maternal blood of intra-uterine growth retarded and appropriate birth weight babies. Eur J Clin Nutr 4, 9391-9399.

Ross DA (2002) Recommendations for vitamin A supplementation. J Nutr 132, 2902S-2906S

Rosso P (1990) Nutrition and Metabolism, Mother and Fetus, 1st ed., Oxford: Oxford University Press.

Sann L, Bienvenu J, Lahet C, Divry P, Cotte J \& Bethenod M (1981) Serum orosomucoid concentration in newborn infants. Eur J Pediatr 136, 181-185.

Shenai JP (1989) Vitamin A metabolism in the preterm infant. In Textbook of Gastroenterology and Nutrition in Infancy, 2nd ed. pp. 367-375 [E Lebenthal, editor]. New York: Raven Press.

Shenai JP, Chytil F, Jhaveri A \& Stahlman MT (1981) Plasma vitamin $\mathrm{A}$ and retinol binding protein in premature and term neonates. J Pediatr 99, 302-305.

Smith FR \& Goodman WS (1971) The effects of diseases of the liver, thyroid and kidneys on the transport of vitamin A in human plasma. J Clin Invest 50, 2426-2436.

Surks MI \& Oppenheimer JH (1964) Post operative changes in the concentration of thyroxine-binding prealbumin and serum free thyroxine. J Clin Endocrinol 24, 794-802.
Thompson D, Milford-Ward A \& Whicher JT (1992) The value of acute phase protein measurements in clinical practice. Ann Clin Biochem 29, 123-131.

Thurnham DI, McCabe GP, Northrop-Clewes CA \& Nestel P (2002) A meta-analysis of 15 studies to quantify the effects of sub-clinical infection on plasma retinol concentrations to assess the prevalence of vitamin A deficiency. Lancet (In the Press).

Thurnham DI, Northrop-Clewes CA \& Chopra M (1998) Biomarkers in vegetable and fruit intakes. Am J Clin Nutr 68, 756-757.

Thurnham DI, Northrop-Clewes CA, Paracha PI \& McLoone UJ (1997) The possible significance of parallel changes in plasma lutein and retinol in Pakistani infants during the summer season. Br J Nutr 78, 775-784.

Thurnham DI \& Singkamani R (1991) The acute phase response and vitamin A status in malaria. Trans $R$ Soc Trop Med Hyg $\mathbf{8 5}$, 194-199.

Thurnham DI, Smith E \& Flora PS (1988) Concurrent liquid chromatographic assay of retinol, $\alpha$-tocopherol, $\alpha$-carotene, $\beta$-carotene, lycopene and $\beta$-cryptoxanthin in plasma, with tocopherol acetate as internal standard. Clin Chem 2, 377-381.

Tolba AM, Hewedy FM, Al Senaidy AM \& Al Othman AA (1998) Neonates' vitamin A status in relation to birth weight, gestational age and sex. J Trop Pediatr 44, 174-177.

United Nations International Children's Emergency Fund (1994) The Nutritional Status of Women and Children in Nigeria. Lagos: UNICEF.

Uzoechina ON \& Okoro BA (1994) Serum vitamin A status of pre-school children in Nigerian rural community. Ann Trop Paediatr 14, 157-161.

Valquist A, Rask L, Peterson PA \& Berg T (1975) The concentrations of retinol-binding protein, prealbumin and transferrin in the sera of newly delivered mothers and children of various ages. Scand J Clin Lab Invest 35, $569-575$.

Viani A, Rizzo G, Carrai M \& Pacfici Gm (1992) Interindividual variability in the concentrations of albumin and alpha-1-acid glycoprotein in patients with renal disease, newborns and healthy subjects: implications for binding of drugs. Int J Clin Pharmacol Ther Toxicol 30, 128-133.

Wahid MA \& Shadia AHF (1987) Nutrition and the unborn baby. Res Clin Lab 17, 199-206.

World Health Organization (1996) Indicators for Assessing Vitamin A Deficiency and Their Application in Monitoring and Evaluating Intervention Programmes, NUT 96.10. pp. 1-77. Geneva: WHO. 